His second principle is that a given species, or other appropriate taxonomic unit, 'tends' to produce the same antibioties whenever it is isolated, and that in consequonce, rapid identification of organisms can accelerate screening procedures, preventing to some extent the continual rediscovery of a known antibiotic. If such a procedure were used too rigidly of course new antibiotics might be missed. This principle would be most useful where fungi and bacteria are being screened; in the case of Actinomycetes, identification of the antibiotio produced may frequently be more cortain and more rapid than identification of the producing organisms.

His third principle is that test organisms used in screening procedures should include some chosen to detect solective inhibition of specific biochemical mechanisms. Prof. Gause illustrates this by his own work at the Institute of Antibiotics, Moseow, using mutant bacteria and protozoa with impaired respiratory pathways. He considers that these are in some ways analogous to tumour cells, basing this view on the work of Otto Warburg, and therefore proposes the use of such mutants in screening for antibiotics with anti-tumour properties. It seems to me somewhat riaive to base a scarch for anti-tumour substances on so simple a biochemical lesion in the test organism. Nevertheless, tho data presented on their specific sensitivity to known tumour inhibitors are suggestive. But, whatever one may think of this particular instance, the general principle, that test-organisms with known biochemical lesions may be valuable in the scarch for antibiotics with specific properties, is undoubledly valid.

In conclusion, though there is much in this book that is controversial, and much that one feels in. clined to treat with reserve until more evidence is available, it is stimulating reading, and should be read by everyone interested in antibiotics.

P. W. BRIAN

\section{DIPHENYLPROPYLAMINES AS ANALGESICS}

\section{Synthetic Analgesics}

By Paul A. J. Janssen. Part 1: Diphenylpropyl. amines. (International Series of Monographs on Organic Chemistry, Vol. 3.) Pp. vii +183 . (London and New York: Pergamon Press, 1960.) 45s. net.

$\mathrm{T}$ HIS book is the third volume of the International Series of Monographs on Organic Chemistry, edited by D. H. R. Barton and W. von Doering. The series is intended to cover a wide variety of aspects of organic chemistry in the form of concise summaries containing all relevant literature references. It is with this premise in mind that the book should bo read, since it deals with a rather specialized topic, namely, the role of diphenylpropylamines of the type :

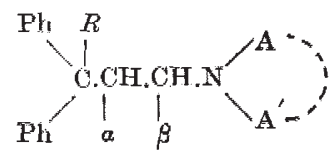

in tho analgesic ficld.
It is an astonishing fact that although the analgesic methadone, which possesses the diphenylpropylamine structure, was discovered by the original German workers in this field during the Second World War, an apparently unabated stream of related compounds displaying not only analgesic but also a wide variety of other pharmacological aetivitics has been appearing ever since. It is against this background of intensive and prolonged rescarch by Paul A. J. Janssen and many other workers in various countries that this book has been written.

The first two chapters are concerned with some ideas on the nature of analgesic activity and the relative potencies of four of the best-known analgesics. 'The next sixteen chapters each deal with the synthesis and properties of compounds with one variant of the group $R$ and are rounded off by a chapter on a few less-important varianis. There follows a small chapter on dissociation constants, which have been regarded as being of possible significance in the activity of such compounds. The book is completed by $a$ brief treatment of the work of $A$. H. Beckett and his collaborators, who postulate that the absolute configuration of all analgesically active optical isomers is identical and related to the configuration of $D-(\cdots)$-nlanino.

A valuable feature of the book is a tabulated survey of physical properties and analgesic potency ratios, moasured against a few well-known analgesics, of all the diphenylpropylamines reported in the literature. That the main tables cover about 100 of the 183 pages of the book gives some idea of the tromendous amount of work done in this fiold. Despite this, the author is frequently able to suggest further areas of research.

The accuracy of a book so full of facts requires much time to check, but spot checks and my personal knowledge of the subject revealed no gross deficiencies, either in subject-matter or literature references. There are a few minor errors. For example, on p. 111, during a discussion on preparative methods, there is some confusion of nomenclature, formula 7.4 on p. 123 has a vital bond missing, the description of the reaction sequence on p. 120 is confused by an incorrect formula reference, "amine" instead of "amide" appears at the beginning of Chapter 11, ref. 87 on p. 132 should be 88 , and ' $J$. Org. Chem.' is omitted from ref. 317 . However, in general, the errors are obvious and do not detract from the readability of the book. The correlation between the tabulated compounds and the structures discussed in individual chapters could possibly have been improved by the use of a common numbering system, but no great difficulty is involved on this score.

Dr. Janssen has written a thoughtful, analytical book which, although well confined to the subject. matter of the title, gives several glimpses of the many other pharmacological activities which modification of these propylamines produces. The reader may well detect a bint of the excitement which can be experienced during the investigation of structure-activity relationships in a successful line of research.

Tho book is recommended as being of value to the increasingly large number of those concerned with medicinal chemistry, as a concise method of following the work in this field. In addition, apart from its general interest, a number of chemically interesting points make it worth the attention of other chemists. J. W. BiLLINGHURST 